\title{
Complement-mediated microangiopathy in IgA nephropathy and IgA vasculitis with nephritis
}

\author{
Jamie S. Chua $\mathbb{1}^{1} \cdot$ Malu Zandbergen ${ }^{1} \cdot$ Ron Wolterbeek $^{2} \cdot$ Hans J. Baelde $^{1} \cdot$ Leendert A. van Es $^{1}$ • \\ Johan W. de Fijter ${ }^{3} \cdot$ Jan A. Bruijn ${ }^{1}$. Ingeborg M. Bajema ${ }^{1}$
}

Received: 12 December 2018 / Revised: 18 February 2019 / Accepted: 18 February 2019 / Published online: 1 April 2019

(c) United States \& Canadian Academy of Pathology 2019

\begin{abstract}
Complement factor C4d was recently observed in renal biopsies from patients who had IgA nephropathy and a poor prognosis. We previously reported that $\mathrm{C} 4 \mathrm{~d}$ is a common denominator in microangiopathies. In this retrospective cohort study, we investigated whether $\mathrm{C} 4 \mathrm{~d}$ is a marker of microangiopathy in both $\operatorname{IgA}$ nephropathy and $\operatorname{IgA}$ vasculitis with nephritis, and whether patients with $\mathrm{C} 4 \mathrm{~d}$ and microangiopathy have poor renal outcome. We examined 128 renal biopsies from adult and pediatric patients, including normotensive and hypertensive patients, who presented with IgA nephropathy or IgA vasculitis with nephritis. Biopsies were re-evaluated in accordance with the Oxford classification, scored for additional lesions, and stained for complement proteins using immunohistochemistry, including C4d and C5b-9. Clinical data were collected with a mean $( \pm$ SD) follow-up period of $51 \pm 39$ months. Changes in estimated glomerular filtration rate over time were compared using linear mixed-effects models. Renal survival was analyzed using multivariable Cox regression. Microangiopathic lesions were present in $20 \%$ of all biopsies $(23 \%$ and $9 \%$ of patients with $\operatorname{IgA}$ nephropathy and $\operatorname{IgA}$ vasculitis with nephritis, respectively). Microangiopathy was associated with C4d and C5b-9 deposits, a higher number of chronic lesions, and hypertension (all $p<0.05$ ). Patients with $\mathrm{C} 4 \mathrm{~d}$ and microangiopathic lesions had significantly poorer renal survival than patients without these findings, corrected for hypertension $(p<0.01)$. In conclusion, patients with $\operatorname{IgA}$ nephropathy or IgA vasculitis with nephritis with a combination of $\mathrm{C} 4 \mathrm{~d}$ positivity and microangiopathy comprise a clinical subgroup with an increased number of chronic lesions, lower estimated glomerular filtration rate, and poorer renal survival, even when corrected for hypertension. These data suggest that complement activation is involved in the development of microangiopathy in patients with IgA nephropathy and IgA vasculitis with nephritis, and that complement-mediated microangiopathy contributes to disease progression.
\end{abstract}

Supplementary information The online version of this article (https:// doi.org/10.1038/s41379-019-0259-z) contains supplementary material, which is available to authorized users.

Jamie S. Chua

j.s.chua@lumc.nl

1 Department of Pathology, Leiden University Medical Center, Leiden, The Netherlands

2 Medical Statistics, Department of Biomedical Data Sciences, Leiden University Medical Center, Leiden, The Netherlands

3 Department of Nephrology, Leiden University Medical Center, Leiden, The Netherlands

\section{Introduction}

Worldwide, immunoglobulin A (IgA) nephropathy is the most common primary glomerulonephritis [1]. The clinical features of $\operatorname{IgA}$ nephropathy include microscopic hematuria with or without macroscopic hematuria, varying amounts of proteinuria, and hypertension. The diagnostic hallmark is a predominance of IgA deposits in the glomerular mesangium on renal biopsy. Light microscopic features vary widely and can be evaluated by the Oxford classification for IgA nephropathy [2, 3]. Similar to glomerular lesions, renal arterial and arteriolar lesions can vary widely, ranging from arteriolar wall thickening and hyaline changes to microangiopathy with or without thrombosis [4-6].

Complement activation is considered to play an important role in the pathogenesis of IgA nephropathy, and various complement proteins have been correlated with disease 
progression in $\operatorname{IgA}$ nephropathy, including differences in the patterns of renal complement protein deposits and/or complement levels in the serum and urine [7, 8]. Furthermore, some patients with IgA nephropathy have been reported to have genetic deficiencies in complementregulatory proteins [7, 9-14]. Moreover, recent case reports suggest that some patients with $\operatorname{IgA}$ nephropathy may benefit from complement-inhibiting therapy [15-18].

Two recent studies involving patients with IgA nephropathy reported that complement activation and microangiopathic lesions, respectively, are important in determining renal outcome [5, 19]. Espinosa et al. [19] found that $\mathrm{C} 4 \mathrm{~d}$-positive staining in glomeruli was present in $20 \%$ of biopsies obtained from patients with IgA nephropathy; in addition, they found that glomerular C4d staining was an independent risk factor for the development of endstage renal disease. El Karoui et al. [5] found that more than half of renal biopsies obtained from patients with $\operatorname{Ig} \mathrm{A}$ nephropathy revealed renal microangiopathy with thrombosis (acute thrombotic microangiopathy) or renal microangiopathy without thrombosis (organized thrombotic microangiopathy without platelet thrombi). Although this prevalence of renal microangiopathy may have been an overestimation relative to the general population-patients were selected at an active hypertensive clinic_- the findings are clinically relevant, as microangiopathy in biopsies with IgA nephropathy was associated with severe hypertension and poor renal outcome [5]. Combining the results from these two studies with our own recent finding that complement factor $\mathrm{C} 4 \mathrm{~d}$ is a common denominator in patients with renal thrombotic microangiopathy [20], we hypothesized that an intricate relationship may exist between complement activation and microangiopathic lesions in IgA nephropathy and IgA vasculitis with nephritis (also known as Henoch-Schönlein purpura nephritis), possibly indicating a subgroup of patients with relatively poor clinical outcome.

\section{Methods}

\section{Patients and clinical data}

We retrospectively searched the archives in the Department of Pathology at Leiden University Medical Center for patients who underwent a renal biopsy from January 2003 through May 2013. The search terms included "IgA nephropathy" and "Henoch-Schönlein". We excluded biopsies from transplanted kidneys, inadequate or missing biopsies, and biopsies from patients with a concomitant kidney disease. Cases were reviewed by an experienced nephropathologist. A diagnosis of IgA nephropathy was based on the predominance of $\operatorname{IgA}$ deposits in the glomerular mesangium [2]. A diagnosis of $\operatorname{IgA}$ vasculitis with nephritis was based on the concurrent presence of palpable purpura [21]. The clinical and laboratory data were obtained retrospectively from the medical records and included patient demographics, blood pressure, the number and type of antihypertensive agents used, serum creatinine, proteinuria, clinical thrombotic microangiopathy, and requirement of renal replacement therapy. For adults, hypertension was defined as systolic blood pressure $\geq 140 \mathrm{mmHg}$, diastolic blood pressure $\geq 90 \mathrm{mmHg}$, or the need for antihypertensive medication to maintain blood pressure below these values [22]. For children and adolescents, hypertension was defined as blood pressure higher than the 95th percentile for the patient's gender, age, and height, which was based on the fourth report on the diagnosis, evaluation, and treatment of high blood pressure in children and adolescents [23]. Malignant hypertension was defined as hypertension with grade 3 or grade 4 hypertensive retinopathy. Clinical thrombotic microangiopathy was defined as the presence of microangiopathic hemolytic anemia (anemia, low haptoglobin levels, schistocytosis, and/or elevated lactate dehydrogenase levels), renal dysfunction, and thrombocytopenia. Mutations in complement-regulatory genes were not tested in this historic cohort. Estimated glomerular filtration rate was determined in adults using the simplified Modification of Diet in Renal Disease (MDRD) formula; estimated glomerular filtration rate was determined in children and adolescents using the bedside Schwartz formula [24, 25]. For each patient, the date of renal biopsy was used as the patient's baseline data point.

\section{Renal biopsy evaluation}

The renal tissue was fixed in $10 \%$ buffered formalin, embedded in paraffin, and sectioned. Paraffin-embedded sections were stained with Masson's trichrome, hematoxylin and eosin, periodic acid-Schiff, and silver stain using standard protocols. The biopsies were re-evaluated in accordance with the Oxford classification for $\operatorname{Ig} \mathrm{A}$ nephropathy using the MEST-C criteria (mesangial hypercellularity, endocapillary hypercellularity, segmental glomerulosclerosis, tubular atrophy/interstitial fibrosis, and crescents) [2, 26]. Microangiopathic lesions were scored as microangiopathy with or without thrombosis [5, 27]. Active microangiopathy was defined as follows: the presence of fibrin, endothelial swelling or denudation, mesangiolysis, or microaneurysms in the glomeruli; thrombi, endothelial swelling or denudation, intramural fibrin or intimal swelling in the arterioles; thrombi or myxoid intimal swelling in the arteries. Chronic microangiopathy was defined as follows: the presence of fibrous intimal thickening with concentric lamination and/or recanalization in the arterioles or arteries; these lesions may or may not be accompanied by double contours in glomerular peripheral capillary walls. Arterial 
intimal sclerosis was scored semi-quantitatively on a scale from 0 to 4 (0, absent; 1 , arterial intimal sclerosis without luminal occlusion; 2, arterial intimal sclerosis with 1-25\% luminal occlusion; 3 , arterial intimal sclerosis with 26-50\% luminal occlusion; 4, arterial intimal sclerosis with $>50 \%$ luminal occlusion). Arteriolar hyalinosis was scored semi-quantitatively on a scale from 0 to 2 ( 0 , absent; 1 , mild, non-occlusive hyalinosis; 2 , severe, extensive, and/ or occlusive hyalinosis).

\section{Immunostaining}

To measure human renal complement activation and colocalization, we performed immunostaining for various complement proteins on adjacent kidney sections as previously described [20]. In brief, 4- $\mu$ m-thick paraffinembedded sections were prepared, deparaffinized, and subjected to antigen retrieval. After blocking endogenous peroxidases, the sections were incubated in the relevant primary antibody for $1 \mathrm{~h}$. Binding of the primary antibody was visualized using the appropriate horseradish peroxidase-labeled secondary antibodies and diaminobenzidine as the chromogen. Finally, the sections were counterstained with hematoxylin. For immunohistochemistry, we used primary antibodies against the following proteins: C4d (BI-RC4d; Biomedica Gruppe, Vienna, Austria; 1:50), a cleavage product of $\mathrm{C} 4$ that binds covalently to the target tissue and can arise from the classical and mannose-binding lectin pathways; C1q (A0136; Dako, Glostrup, Denmark; 1:800), which reflects activation of the classical complement pathway; MBL (HPA002027; SigmaAldrich, St. Louis, MO; 1:500) which reflects activation of the lectin pathway; and sC5b-9 (A239; Quidel, San Diego, CA; 1:150) which reflects the terminal complement pathway and can be formed after activation of any of the three complement pathways. Twelve biopsies lacked sufficient paraffin-embedded tissue for immunostaining; these cases were excluded from the subanalyses. For Factor B and MBL, frozen sections were acetone-fixed, then incubated for $1 \mathrm{~h}$ with antibodies against Factor B (a227; Quidel, San Diego, CA; 1:400) and MBL (mAb 3E7; Hycult Biotech, Uden, the Netherlands; 1:200). Fifty-one biopsies had insufficient frozen tissue for Factor B and MBL analyses; these cases were excluded from the subanalyses. For each staining protocol, the optimum antibody dilution and incubation time were determined empirically for each antibody by performing a titration experiment using positive control sections.

\section{Quantification of immunostaining}

For complement proteins, two independent observers who were blinded with respect to the subjects' clinical data scored immunostained renal sections. We scored both the glomeruli and arterioles in each section. In non-sclerotic segments of glomeruli, immunostaining was scored as absent (representing either an absence or trace levels of staining) or present in the mesangium, peripheral glomerular capillary walls, or both. If immunostaining was present, each biopsy was further classified as having either focal ( $\leq 50 \%$ of glomeruli) or diffuse $(>50 \%$ of glomeruli) deposits, the staining in the majority of positive glomeruli was classified as either segmental or global glomerular staining. In the arterioles, immunostaining was scored as either absent or present, with present defined as circumferential staining along the vessel lumina; positivity only present along the elastic lamina was excluded. Finally, for each stain an overall score was given to a biopsy sample, combining the scores obtained for the glomeruli and arterioles; biopsy samples could be "negative" (no staining in glomeruli or arterioles) or "positive" (staining in glomeruli, arterioles, or both). In addition, $\operatorname{IgA}, \operatorname{IgG}$, and $\operatorname{IgM}$ staining scores were obtained from the pathology reports and were re-scored as absent (for a score of 0 or trace staining) or present (for a score of 1,2 , or $3+$ ).

\section{Statistical analysis}

Proportions were analyzed using the chi-square test or Fisher's exact test, where appropriate. Continuous variables were analyzed using the unpaired Student's $t$-test. Changes in the estimated glomerular filtration rate over time were compared using a linear mixed-effects model with random intercept and random slopes, to account for the repeated measurements of variables obtained from the same individual. For this analysis we tested interactions, including group-by-time interactions, and excluded nonsignificant interactions from the model. Renal survival was analyzed using Cox regression and the log-rank test. Renal survival is presented as a Kaplan-Meier curve without adjustment for baseline covariates. The predictive values of $\mathrm{C} 4 \mathrm{~d}$ and interstitial fibrosis/tubular atrophy in Cox regression models was assessed using Harrell's C [28]. All analyses were performed using the SPSS statistical software package (version 20.0; IBM Corp.). Differences with $p<0.05$ were considered to be statistically significant.

\section{Ethics}

The study was conducted in accordance with the Declaration of Helsinki, and all biopsies were coded and then handled and analyzed anonymously in accordance with the Dutch National Ethics Guidelines (Code for Proper Secondary Use of Human Tissue, Dutch Federation of Medical Scientific Societies). 


\section{Results}

\section{Biopsy search}

Our search strategy yielded 220 renal biopsies of which tissue was available. We excluded 70 transplant biopsies, 14 cases with inadequate biopsy samples, 5 cases with renal comorbidity, and 3 follow-up biopsies. Thus, we included a total of 128 native renal biopsies from 128 patients who were diagnosed with IgA nephropathy or IgA vasculitis with nephritis.

\section{Total cohort}

The patient characteristics of the study cohort are summarized in Table 1 . The mean $( \pm \mathrm{SD})$ follow-up period was $51 \pm 39$ months. Microangiopathy was present in 26 of the 128 biopsies $(20.3 \%)$ with IgA nephropathy or IgA vasculitis with nephritis. When present, microangiopathy was focal, and localized in glomeruli (in 4 biopsies; 15\%), in arterioles (in 21 biopsies; $81 \%$ ), or in both (in 1 biopsy; $4 \%$ ). Active microangiopathy was present in 9 biopsies (35\%) and chronic microangiopathy was present in 17 biopsies $(65 \%)$ (Fig. 1). In the group of 22 pediatric patients, microangiopathy was observed in 1 of 15 cases with IgA nephropathy, but not in the 7 patients with $\operatorname{IgA}$ vasculitis with nephritis.

\section{Clinical differences at time of biopsy}

The patients with microangiopathy had significantly lower estimated glomerular filtration rate values at the time of biopsy than the patients without microangiopathy (the mean values were 37.7 and $63.9 \mathrm{~mL} / \mathrm{min} / 1.73 \mathrm{~m}^{2}$, respectively; $p<0.001$ ) (Table 1). Although the pediatric patients had a significantly lower prevalence of microangiopathy in
Table 1 Clinical characteristics at the time of biopsy

\begin{tabular}{|c|c|c|c|c|}
\hline & $\begin{array}{l}\text { Microangiopathy } \\
\text { absent } \\
n=102\end{array}$ & $\begin{array}{l}\text { Microangiopathy } \\
\text { present } \\
n=26\end{array}$ & $\begin{array}{l}\text { Total } \\
n=128\end{array}$ & $p$ value \\
\hline Diagnosis & & & & 0.126 \\
\hline IgA nephropathy, $n(\%)$ & $81(79)$ & $24(92)$ & $105(82)$ & \\
\hline IgA vasculitis with nephritis, $n(\%)$ & $21(21)$ & $2(8)$ & $23(18)$ & \\
\hline Female patients, $n(\%)$ & $32(31)$ & $7(27)$ & $39(31)$ & 0.660 \\
\hline Pediatric patients, $n(\%)$ & $21(21)$ & $1(4)$ & $22(17)$ & 0.043 \\
\hline Age, years & $41.1 \pm 22.1$ & $45.9 \pm 15.6$ & $42.1 \pm 21.0$ & 0.203 \\
\hline Clinical thrombotic microangiopathy, $n(\%)$ & $0(0)$ & $1(4)$ & $1(1)$ & 0.203 \\
\hline Malignant hypertension, $n(\%)$ & $2(2)$ & $2(8)$ & $4(3)$ & 0.183 \\
\hline Hypertension, $n(\%)$ & $50(49)$ & $20(77)$ & $70(55)$ & 0.011 \\
\hline Systolic blood pressure $(\mathrm{mmHg})$ & $136.2 \pm 25.4$ & $153.0 \pm 34.1$ & $139.7 \pm 28.1$ & 0.006 \\
\hline Diastolic blood pressure $(\mathrm{mmHg})$ & $79.6 \pm 15.7$ & $93.5 \pm 20.7$ & $82.5 \pm 17.7$ & $<0.001$ \\
\hline Number of antihypertensive drugs taken & $0.9 \pm 1.1$ & $1.4 \pm 1.1$ & $1.0 \pm 1.1$ & 0.042 \\
\hline \multicolumn{5}{|l|}{ Type of antihypertensive drugs ${ }^{\mathrm{a}}$} \\
\hline None, $n(\%)$ & $52(52)$ & $7(27)$ & $59(47)$ & 0.033 \\
\hline $\begin{array}{l}\text { Angiotensin-converting enzyme inhibitor } \\
\text { and/or angiotensin-receptor blocker, } n(\%)\end{array}$ & $34(34)$ & $16(62)$ & $50(40)$ & \\
\hline Other, $n(\%)$ & $14(14)$ & $3(11)$ & $17(13)$ & \\
\hline Use of corticosteroids, $n(\%)$ & $42(41)$ & $10(39)$ & $52(41)$ & 0.801 \\
\hline Proteinuria (g/day) & $1.93 \pm 2.37$ & $3.25 \pm 2.31$ & $2.29 \pm 2.41$ & 0.035 \\
\hline Serum creatinine in adults $(\mathrm{mg} / \mathrm{dL})$ & $2.2 \pm 2.7$ & $2.8 \pm 2.4$ & $2.4 \pm 2.7$ & 0.328 \\
\hline Serum creatinine in children $(\mathrm{mg} / \mathrm{dL})$ & $0.7 \pm 0.3$ & 0.4 & $0.7 \pm 0.3$ & 0.423 \\
\hline $\begin{array}{l}\text { Estimated glomerular filtration rate }(\mathrm{mL} / \\
\left.\mathrm{min} / 1.73 \mathrm{~m}^{2}\right)\end{array}$ & $63.9 \pm 41.3$ & $37.7 \pm 25.3$ & $58.6 \pm 39.9$ & $<0.001$ \\
\hline $\operatorname{Ig} \mathrm{A}(\mathrm{g} / \mathrm{L})$ & $3.5 \pm 1.6$ & $3.5 \pm 1.4$ & $3.5 \pm 1.5$ & 0.950 \\
\hline Serum IgA: C3 & $3.1 \pm 2.0$ & $2.8 \pm 1.2$ & $3.1 \pm 1.9$ & 0.702 \\
\hline Serum C3 (g/L) & $1.2 \pm 0.3$ & $1.1 \pm 0.2$ & $1.2 \pm 0.3$ & 0.425 \\
\hline Serum C4 (mg/L) & $265.3 \pm 113.7$ & $232.3 \pm 74.6$ & $260.3 \pm 108.8$ & 0.434 \\
\hline
\end{tabular}

${ }^{\mathrm{a}}$ Data on antihypertensive treatment was not available for two patients. Values are expressed as the mean \pm $\mathrm{SD}$ or number $(\%)$ 

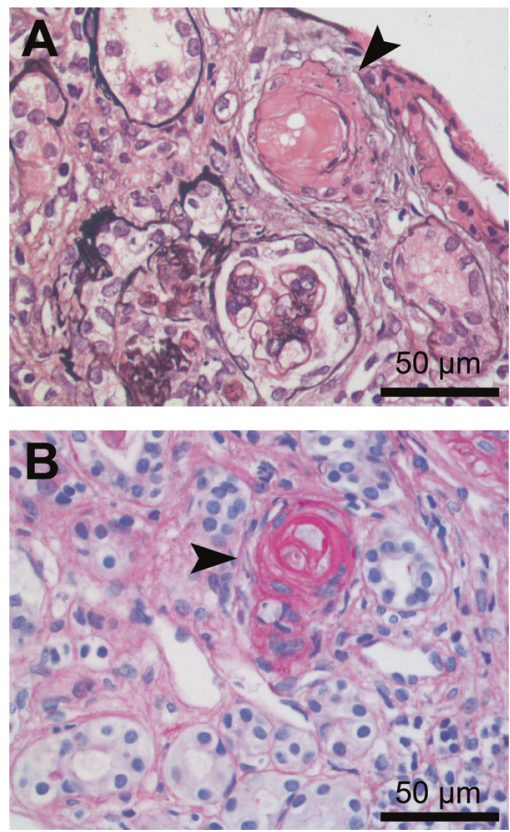

Fig. 1 Typical examples of active and chronic microangiopathy. Typical example of a renal biopsy with active microangiopathy with thrombosis (a), showing a microthrombus (arrowhead) in an arteriole in the absence of inflammatory changes. Typical example of a renal biopsy with chronic microangiopathy (b), showing an organized thrombus (arrowhead) in the vessel wall with recanalization, and obliteration of the vessel lumen due to intimal hyperplasia. a: silver stain, original maginifcation $\times 400$. b: Periodic acid-Schiff stain, original magnification $\times 400$

their biopsy samples than the adults $(p<0.05)$, no significant difference was found with respect to mean age between the patients with microangiopathy and the patients without microangiopathy $(p=0.203)$. The prevalence of hypertension was higher among patients with microangiopathy $(77 \%)$ than among patients without microangiopathy (49\%; $p<0.05)$. Notably, 6 of the 26 patients with microangiopathy (23\%) were normotensive; these patients either used no medication $(n=3)$ or used only angiotensinconverting enzyme inhibitors $(n=1)$ or angiotensinreceptor blockers $(n=2)$ for persistent proteinuria. One of 26 patients with microangiopathy (4\%) had clinical evidence for systemic thrombotic microangiopathy. Two other patients with microangiopathy had malignant hypertension, and one additional patient had preeclampsia and HELLP (hemolysis, elevated liver enzyme levels, and low platelet levels) syndrome noted in the medical history but absent at the time of biopsy. No other potential causes of systemic thrombotic microangiopathy (such as antiphospholipid syndrome, a history of drug-induced thrombotic microangiopathy, mutations in complement-regulatory genes, or infection with Shiga toxin-producing bacteria) were documented in our cohort. Eleven patients had evidence of liver disease prior to the diagnosis of $\operatorname{IgA}$ nephropathy $(n=9)$ or
IgA vasculitis with nephritis $(n=2)$, these are described in Supplemental Table S1.

\section{Renal biopsy findings}

In the renal biopsies, chronic lesions such as global glomerulosclerosis or tubular atrophy and interstitial fibrosis were more prevalent in biopsies with microangiopathy than in biopsies without microangiopathy $(p<0.01)$ (Table 2). The prevalence and severity of arterial intimal sclerosis and arteriolar hyalinosis were significantly higher among the patients with microangiopathy than among patients without microangiopathy ( $p$ values $<0.01)$. No significant histopathological differences were observed between cases with respect to active microangiopathy versus chronic microangiopathy. Crescents were observed in 6 of 23 cases with IgA vasculitis with nephritis (26\%) and in 11 of 105 cases with $\operatorname{IgA}$ nephropathy (10\%). This difference was statistically significant $(p=0.046)$. In the renal biopsies from the two IgA vasculitis with nephritis cases with microangiopathy, one had crescents and the other did not. Both cases progressed to end-stage renal disease and required renal replacement therapy. In addition to the predominance of IgA deposits, glomerular deposits of $\operatorname{IgG}$ and $\mathrm{IgM}$ were observed in $8 \%$ and $30 \%$ of all renal biopsies, respectively; no significant differences were observed between cases with microangiopathy and cases without microangiopathy. Among the 26 cases with microangiopathy, only 2 patients had weak $(1+)$ staining intensity of IgA by immunofluorescence; both cases had mesangial hypercellularity. Deposits of C4d, C5b-9, and $\mathrm{C} 1 \mathrm{q}$ in the glomeruli and/or arterioles were more prevalent in the patients with microangiopathy than in the patients without microangiopathy (Table 3). Typical examples of complement staining in IgA nephropathy are shown in Fig. 2 and Supplemental Fig. S1. Complement proteins were co-localized with microthrombi (Fig. 2c, d). Glomerular $\mathrm{C} 4 \mathrm{~d}$ deposition was associated with $\mathrm{C} 1 \mathrm{q}$ and $\mathrm{IgM}$ deposits ( $p<0.001$ and $p<0.05$, respectively), but not with IgG or MBL deposits.

\section{Clinical differences at follow-up}

The follow-up duration was similar between patients with microangiopathy and patients without microangiopathy $(48.4 \pm 36.2$ and $51.5 \pm 39.2$ months, respectively; $p=$ 0.717). Patients with a combination of $\mathrm{C} 4 \mathrm{~d}$ and microangiopathy had significantly poorer renal survival than patients who lacked these findings $(p<0.01)$ (Fig. 3). Cox proportional hazard regression analysis revealed that this difference in renal survival remained significant after we corrected for hypertension (Table 4), estimated glomerular filtration rate, and interstitial fibrosis with tubular atrophy, 
Table 2 Renal biopsy characteristics
Table 3 Complement proteins in biopsies of patients with or without microangiopathy

\begin{tabular}{|c|c|c|c|c|}
\hline & $\begin{array}{l}\text { Microangiopathy } \\
\text { absent } \\
n=102\end{array}$ & $\begin{array}{l}\text { Microangiopathy } \\
\text { present } \\
n=26\end{array}$ & $\begin{array}{l}\text { Total } \\
n=128\end{array}$ & $p$ value \\
\hline $\begin{array}{l}\text { Percentage of glomeruli with global } \\
\text { sclerosis, mean } \pm \text { SD }\end{array}$ & $13 \pm 18$ & $33 \pm 26$ & $17 \pm 22$ & 0.001 \\
\hline Mesangial hypercellularity (M1) & $49(48)$ & $18(69)$ & $67(52)$ & 0.053 \\
\hline Endocapillary proliferation (E1) & $26(25)$ & $11(42)$ & $37(29)$ & 0.091 \\
\hline Segmental glomerulosclerosis (S1) & $41(40)$ & $16(62)$ & $57(45)$ & 0.051 \\
\hline $\begin{array}{l}\text { Tubular atrophy and interstitial } \\
\text { fibrosis }(\mathrm{T})\end{array}$ & & & & $<0.001$ \\
\hline$\leq 25 \%(\mathrm{~T} 0)$ & $63(62)$ & $8(31)$ & $71(56)$ & \\
\hline $26-50 \%(\mathrm{~T} 1)$ & $28(27)$ & $3(11)$ & $31(24)$ & \\
\hline$>50 \%(\mathrm{~T} 2)$ & $11(11)$ & $15(58)$ & $26(20)$ & \\
\hline Crescents (C) & & & & 0.550 \\
\hline Absent (C0) & $87(85)$ & $24(92)$ & $111(87)$ & \\
\hline $1-24 \%$ of glomeruli (C1) & $12(12)$ & $2(8)$ & $14(11)$ & \\
\hline$\geq 25 \%$ of glomeruli (C2) & $3(3)$ & $0(0)$ & $3(2)$ & \\
\hline Glomerular necrosis, $n(\%)$ & $4(4)$ & $0(0)$ & $4(3)$ & 0.582 \\
\hline Arteriolar hyalinosis, $n(\%)$ & $29(28)$ & $15(58)$ & $44(34)$ & 0.010 \\
\hline Arterial intimal sclerosis ${ }^{\mathrm{a}}, n(\%)$ & $23(24)$ & $21(81)$ & $44(36)$ & $<0.001$ \\
\hline
\end{tabular}

${ }^{\mathrm{a}}$ Arterial intimal sclerosis was not scored in seven biopsies that lacked arterial branches

\begin{tabular}{cccrc}
\hline & $\begin{array}{l}\text { Microangiopathy absent } \\
n=94\end{array}$ & $\begin{array}{l}\text { Microangiopathy present } \\
n=22\end{array}$ & $\begin{array}{l}\text { Total } \\
n=116\end{array}$ & $p$ value \\
\hline C4d positive, $n(\%)$ & $16(17)$ & $17(77)$ & $33(28)$ & $<0.001$ \\
In glomeruli, $n(\%)$ & $14(15)$ & $12(55)$ & $26(22)$ & $<0.001$ \\
In arterioles, $n(\%)$ & $5(5)$ & $11(50)$ & $16(14)$ & $<0.001$ \\
C5b-9 positive, $n(\%)$ & $44(47)$ & $16(73)$ & $60(52)$ & 0.029 \\
In glomeruli, $n(\%)$ & $11(12)$ & $6(27)$ & $17(15)$ & 0.063 \\
In arterioles, $n(\%)$ & $43(46)$ & $15(68)$ & $58(50)$ & 0.058 \\
C1q positive, $n(\%)$ & $34(36)$ & $13(59)$ & $47(41)$ & 0.049 \\
In glomeruli, $n(\%)$ & $30(32)$ & $10(46)$ & $40(35)$ & 0.229 \\
In arterioles, $n(\%)$ & $8(9)$ & $6(27)$ & $14(12)$ & 0.015 \\
MBL positive, $n(\%)$ & $2(2)$ & $0(0)$ & $1(2)$ & 0.490 \\
In glomeruli, $n(\%)$ & $1(1)$ & $0(0)$ & $1(1)$ & 0.627 \\
In arterioles, $n(\%)$ & $1(1)$ & $0(0)$ & $19 / 77(25)$ & 0.627 \\
Factor B positive, $n(\%)$ & $14 / 57(25)$ & $5 / 20(25)$ & $19 / 77(25)$ & 0.969 \\
In glomeruli, $n(\%)$ & $14 / 57(25)$ & $5 / 20(25)$ & $0(0)$ & $\mathrm{NA}$ \\
In arterioles, $n(\%)$ & $0(0)$ & $0(0)$ &
\end{tabular}

$M B L$ mannose-binding lectin, $N A$ not applicable

${ }^{\mathrm{a} F a c t o r} \mathrm{~B}$ was performed on fresh-frozen tissue, which was available for 77 biopsy samples respectively (Supplemental Tables S2 and S3). C4d deposition was not a better predictor than the Oxford $T$ score or the presence of interstitial fibrosis with tubular atrophy (Supplemental Table S4). Linear mixed-effects model analysis revealed that hypertensive patients who have a combination of microangiopathy and $\mathrm{C} 4 \mathrm{~d}$ had a mean estimated glomerular filtration rate of $23.4 \mathrm{~mL} / \mathrm{min} / 1.73 \mathrm{~m}^{2}$ at the time of biopsy (Table 5). After we corrected for hypertension, these patients with both microangiopathy and C4d still had significantly lower estimated glomerular filtration rate values at the time of biopsy compared to patients who lacked both of these findings, leading to a mean estimated glomerular filtration rate of $46.8 \mathrm{~mL} / \mathrm{min} / 1.73 \mathrm{~m}^{2}$ for the latter group. The rate of estimated glomerular filtration 
Fig. 2 Typical examples of complement staining and colocalization with

microangiopathy. Typical examples of complement staining in glomeruli (a) and arterioles (b). C4d staining (c) was co-localized with microangiopathy (d) in the same glomerular capillary (black arrowhead) and arteriole (white arrowhead) of a patient with microangiopathy in sequentially sectioned tissue. a-c show $\mathrm{C} 4 \mathrm{~d}$ staining; $\mathbf{d}$ shows phosphotungstic acid hematoxylin (PTAH) staining, with fibrin staining as deep blue
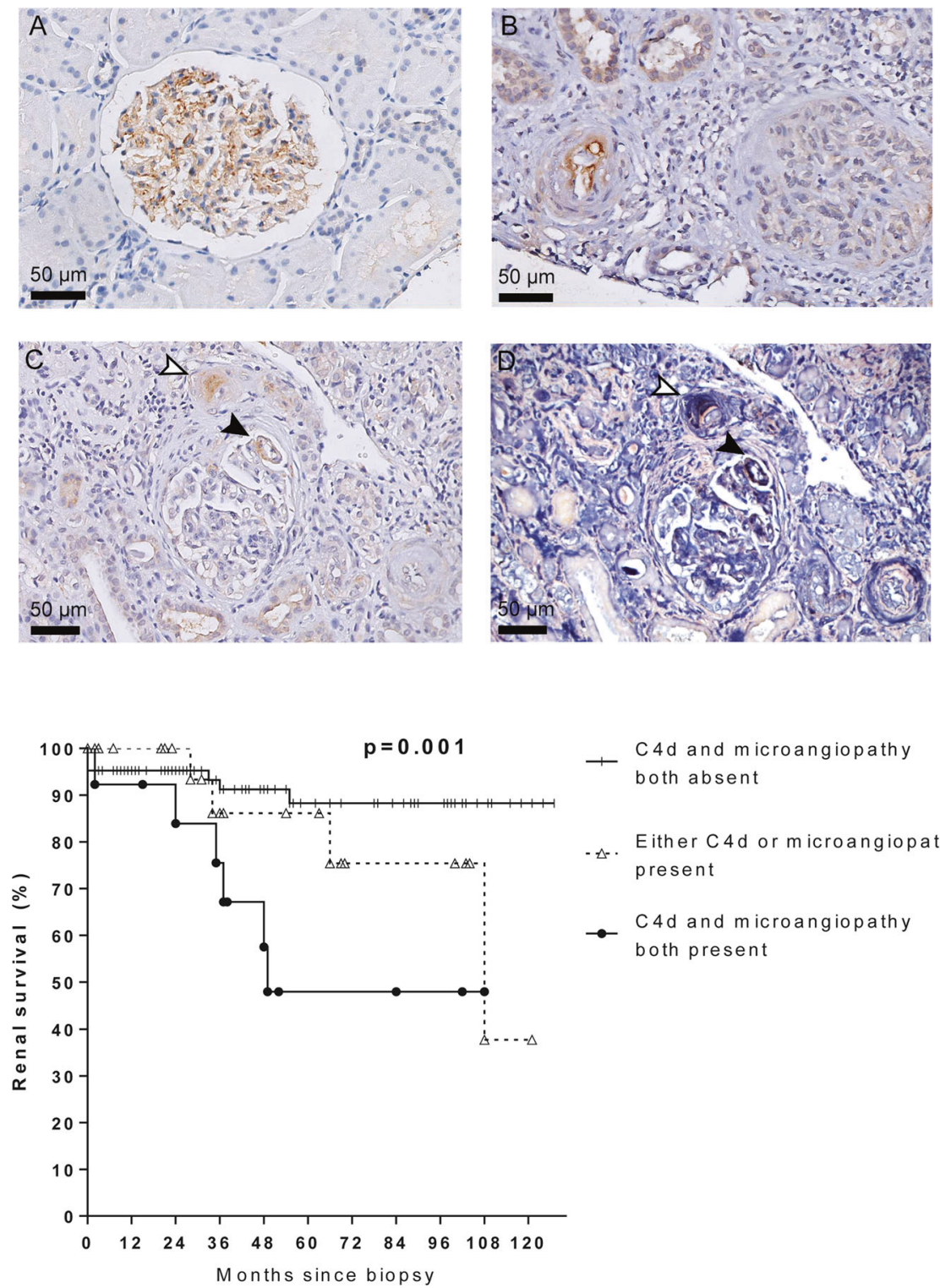

Fig. 3 Renal survival of patients with microangiopathy and $\mathrm{C} 4 \mathrm{~d}$. All patients with IgA nephropathy or $\operatorname{IgA}$ vasculitis with nephritis were divided into three groups based on the presence or absence of microangiopathy and $\mathrm{C} 4 \mathrm{~d}$. Patients in which microangiopathy and $\mathrm{C} 4 \mathrm{~d}$ were both present had significantly lower renal survival than patients in which $\mathrm{C} 4 \mathrm{~d}$ and microangiopathy were both absent $(p=0.001)$
Table 4 Risk factors for renal replacement therapy

\begin{tabular}{llll}
\hline Variable & Hazard ratio & $95 \%$ confidence interval & $p$ value \\
\hline Both microangiopathy and C4d absent & Reference (1.000) & NA & 0.028 \\
Either microangiopathy or C4d present & 2.007 & $0.600-7.193$ & 0.249 \\
Both microangiopathy and C4d present & 4.439 & $1.492-13.207$ & 0.007 \\
Hypertension present & 2.779 & $0.746-10.504$ & 0.127 \\
\hline
\end{tabular}

Multivariable Cox proportional hazard regression analyses. The hazard ratios for requiring renal replacement therapy are shown for microangiopathy and $\mathrm{C} 4 \mathrm{~d}$ staining, corrected for hypertension. NA not applicable rate decline was not significantly different between the groups. Although overall renal survival differed between cases with and without microangiopathy (Supplemental Table S5 and Supplemental Fig. S2), the difference in renal survival did not differ significantly between the cases with active microangiopathy and the cases with chronic microangiopathy (Supplemental Fig. S3).

\section{Discussion}

Here, we report that the presence of microangiopathic lesions in $\operatorname{IgA}$ nephropathy is strongly associated with complement activation in general and with $\mathrm{C} 4 \mathrm{~d}$ deposits in particular. Patients whose renal biopsies show both $\mathrm{C} 4 \mathrm{~d}$ and microangiopathy represent a clinical subgroup with poorer 
Table 5 Change in estimated glomerular filtration rate over time

\begin{tabular}{clll}
\hline Variable & $\begin{array}{l}\text { Estimated glomerular filtration } \\
\text { rate }\left(\mathrm{mL} / \mathrm{min} / 1.73 \mathrm{~m}^{2}\right)\end{array}$ & $\begin{array}{l}\text { 95\% confidence } \\
\text { interval }\end{array}$ & $p$ value \\
\hline Intercept & 23.4 & $7.8-39.1$ & 0.004 \\
Both C4d and microangiopathy absent & +23.4 & $5.2-41.6$ & 0.012 \\
Either C4d or microangiopathy present & +9.3 & -12.0 to 30.7 & 0.388 \\
Both C4d and microangiopathy present & Reference & $\mathrm{NA}$ & $\mathrm{NA}$ \\
Hypertension absent & +42.8 & $30.4-55.1$ & $<0.001$ \\
Hypertension present & Reference & $\mathrm{NA}$ & $\mathrm{NA}$ \\
Time, years & 0.04 & -0.06 to 0.2 & 0.414 \\
\hline
\end{tabular}

Linear mixed-effects model using random intercepts and random slopes. The intercept reflects the mean estimated glomerular filtration rate at baseline for hypertensive patients with microangiopathy and C4d. The table shows adjusted differences to this mean estimated glomerular filtration rate at baseline given the absence of microangiopathy, $\mathrm{C} 4 \mathrm{~d}$, or hypertension. $N A$ not applicable renal outcome compared to patients who lack these findings. Our results underscore the important role that microangiopathy plays in IgA nephropathy and adds a nuanced perspective to previous reports. For example, Chang et al. [4] reviewed the renal pathology reports of 435 cases with IgA nephropathy and found that $2 \%$ of cases had microangiopathy either with or without thrombosis. Nasri et al. [29] and Oruc et al. [30] reported a similar prevalence. In contrast, El Karoui et al. [5] re-examined 128 renal biopsies from patients with IgA nephropathy and found a prevalence of $53 \%$. This higher prevalence may be explained—at least in part-by the fact that El Karoui et al. re-examined the renal biopsies with the specific aim of identifying microangiopathic lesions, as well as the fact that patients were selected from an active hypertensive clinic. Although the patients in our cohort did not come from a hypertension clinic, we re-examined at least four different biopsy sections from each patient and found that $23 \%$ of biopsies with $\operatorname{IgA}$ nephrtopathy had microangiopathy with or without thrombosis, which is higher than we had expected based on other studies [4, 29-31]. Thus, our findings indicate that microangiopathy may be underdiagnosed in clinical practice, which is an important point given our finding that microangiopathy is clinically relevant-specifically, we found that patients with microangiopathy had a higher prevalence of hypertension, a higher number of chronic lesions, and poorer renal outcome compared to patients without microangiopathy.

The precise pathogenic mechanism underlying microangiopathy in the setting of IgA nephropathy and $\operatorname{IgA}$ vasculitis with nephritis remains to be determined. However, case reports indicate that various factors may increase the risk of developing microangiopathy in IgA nephropathy; these factors may include drug toxicity, HELLP syndrome, and the presence of antiphospholipid antibodies [5, 32-37]. Multiple factors may be required to cause microangiopathy in general, and in IgA nephropathy in particular; however, our data provide evidence that complement activation plays an important role in the development of microangiopathy in IgA nephropathy, irrespective of other factors. In this respect, hypertension deserves specific attention here, given that high levels of shear stress induced by hypertension can cause microangiopathic changes [38]. However, in our study, several patients with microangiopathy were normotensive; moreover, only a fraction of patients with malignant hypertension had microangiopathy, and the clinical outcome of patients with both microangiopathy and complement deposits remained significantly worse even after we corrected for hypertension. Therefore, our results suggest that hypertension may not be a primary cause of the microangiopathic lesions. A linking factor in this discussion may be the association between complement-regulatory deficits and hypertension-related microangiopathy reported by Timmermans et al. [39]. They recently described a cohort of patients with biopsy-proven microangiopathy that was attributed clinically to severe hypertension; however, they found that $67 \%$ of patients had a mutation in the genes that encode complement factor $\mathrm{C} 3$ or the complement regulators $\mathrm{CFH}, \mathrm{CFI}$, or CD46, with concomitant evidence of complement activation in vivo, and poor renal outcome [39]. It would therefore be interesting to investigate whether IgA nephropathy patients with hypertension-associated microangiopathy share a similar genetic predisposition with the patients reported by Timmermans et al. [39], particularly given the evidence that disease progression is more rapid in patients who have $\operatorname{IgA}$ nephropathy and a deficiency in complement regulation, as well as case reports describing atypical hemolytic uremic syndrome as a comorbidity in IgA nephropathy [18, 40-43].

In the pathogenesis of IgA nephropathy, complement activation is an important trigger of inflammation and progression, acting predominantly via the lectin and alternative pathways [7, 8]. The presence of the complement cleavage product $\mathrm{C} 4 \mathrm{~d}$ has been shown to predict the progression of 
renal damage in patients with IgA nephropathy [19, 44-47]; however, these results did not take into account vascular lesions. In IgA nephropathy, C4d deposition is generally considered a consequence of lectin pathway activation [47]. Roos et al. [46] demonstrated that C4d deposition was associated with the deposition of various lectin proteins. In our study, we found that microangiopathy was associated with C4d, C1q, and C5b-9 deposits; in contrast, MBL deposits were not detected in most patients, even after we repeated the experiment using different anti-MBL antibodies or using fresh-frozen tissue samples (data not shown). Proteomics-based analyses of laser-captured microdissected glomeruli revealed that the classical pathway components $\mathrm{C} 1 \mathrm{q}, \mathrm{C} 1 \mathrm{r}$, and $\mathrm{C} 1 \mathrm{~s}$ were significantly higher in patients with progressive IgA nephropathy compared to patients with non-progressive IgA nephropathy [48]. These data suggest that $\mathrm{C} 4 \mathrm{~d}$ may reflect activation of both the lectin and classical pathways in IgA nephropathy. In our study, Factor B deposition was observed in $25 \%$ of cases, suggesting activation of the alternative pathway. Evidence of alternative pathway activation is commonly observed in IgA nephropathy [7]. Genome-wide association studies in IgA nephropathy point to a role of deletions of CFHR 1 , CFHR3, and rare CFHR5 variants for IgA nephropathy susceptibility [7]. These genes code for the Factor HRelated proteins (FHR), which may function as competitive antagonists of Factor H, reducing complement regulation. Elevated circulating levels of FHR proteins in patients with IgA nephropathy were shown to predict the progression of renal disease [42]. A possible relationship with the development of microangiopathic lesions remains to be investigated. The mechanism by which the complement pathway is activated in microangiopathy could also be distinct from the mechanism that involves IgA1-containing immune complexes. Severe vascular lesions and shear stress-induced endothelial injury have been shown to activate the classical pathway, and several proteins in the coagulation cascade have bi-directional interactions with the complement system, causing a vicious cycle that can be particularly harmful in patients who lack adequate complement regulation [49, 50]. This is particularly interesting given the recent case reports showing that complement-inhibiting therapeuticswhich are known to benefit patients with systemic microangiopathy - are also beneficial to at least some patients with IgA nephropathy, including patients with complementmediated microangiopathy $[15-18,51]$.

In our study, there were 11 patients with liver disease prior to the diagnosis of IgA nephropathy or IgA vasculitis with nephritis. Because it was uncertain whether these cases were to be considered as "secondary IgA nephropathy", we did not exclude them from the study group. We found no important differences between cases with or without liver disease and all relevant reported associations remained significant in subanalyses in which these cases were excluded (data not shown). Importantly, C4d deposition and microangiopathy remained a subgroup with more chronicity and inferior outcome.

Our study has limitations that warrant discussion. First, serum and DNA samples from our patients were unavailable, limiting our ability to investigate possible risk factors in the development of microangiopathy other than the factors examined during the original clinical work-up. Furthermore, although $\mathrm{C} 4 \mathrm{~d}$ is conducted at a number of institutions worldwide, there is considerable variability in $\mathrm{C} 4 \mathrm{~d}$ staining across institutions [52]. Therefore, our observations on complement deposition need to be validated in other centers using local staining procedures. In addition, evaluation of prognosis was limited by the sample size of 26 patients with microangiopathy, of which only a proportion required renal replacement therapy. Although our data suggest that interstitial fibrosis and tubular atrophy is a better predictor for renal outcome than $\mathrm{C} 4 \mathrm{~d}$, this study lacked sufficient power to examine the incremental effect of microangiopathy and $\mathrm{C} 4 \mathrm{~d}$ deposition in addition to all other known markers of poor prognosis, including clinical data, parameters of the Oxford classification, different treatment modalities, and other biomarkers [3, 53]. Multi-center prospective studies on IgA nephropathy should determine whether $\mathrm{C} 4 \mathrm{~d}$ and microangiopathy have an additional prognostic value to these variables. Moreover, we did not take into account relatively subtle cases with only ultrastructural microangiopathic lesions, as electron microscopy data were not available for most cases. Our study's strengths include the relatively high number of biopsy samples examined specifically for $\mathrm{C} 4 \mathrm{~d}$ and microangiopathy, the long follow-up period, and a study cohort that was not biased with respect to recruiting hypertensive patients. Moreover, we describe the prevalence and clinical significance of microangiopathy in pediatric patients with IgA nephropathy and patients with $\operatorname{Ig}$ A vasculitis with nephritis, both of which had a low prevalence of microangiopathy.

In our cohort of 128 patients with IgA nephropathy or IgA vasculitis with nephritis, microangiopathic lesions were present in $20 \%$ of biopsies, and these lesions were primarily combined with $\mathrm{C} 4 \mathrm{~d}$ deposition, based on a thorough histopathological examination involving multiple levels of the renal biopsy. Patients with IgA nephropathy or IgA vasculitis with nephritis together with $\mathrm{C} 4 \mathrm{~d}$ positivity and microangiopathy comprise a clinical subgroup with a higher number of chronic lesions, lower estimated glomerular filtration rate, and poorer renal survival compared to patients without microangiopathy or $\mathrm{C} 4 \mathrm{~d}$ deposits, even after we corrected for hypertension. These data suggest that complement activation plays an important role in the development of microangiopathy in patients with $\operatorname{IgA}$ nephropathy and IgA vasculitis 
with nephritis, and that complement-mediated microangiopathy contributes to disease progression.

Acknowledgements We are grateful to Annelies E. Berden, Marjolijn van Buren, Jade Chantharasy, Karlien Cransberg, Hans C. Ablij, Stefan P. Berger, Bas A. Gabreëls, Hans G. Peltenburg, and Yvo W.J. Sijpkens for their help obtaining the clinical data that were used in this study. The results presented in this paper have not been published previously except in abstract form at Kidney Week 2015, the Annual American Society of Nephrology Conference.

\section{Compliance with ethical standards}

Conflict of interest The authors declare that they have no conflict of interest.

Publisher's note: Springer Nature remains neutral with regard to jurisdictional claims in published maps and institutional affiliations.

\section{References}

1. Wyatt RJ, Julian BA. IgA nephropathy. $\mathrm{N}$ Engl J Med. 2013;368:2402-14.

2. Cattran DC, Coppo R, Cook HT, Feehally J, Roberts IS, Troyanov $\mathrm{S}$, et al. The Oxford classification of IgA nephropathy: rationale, clinicopathological correlations, and classification. Kidney Int. 2009;76:534-45.

3. Trimarchi H, Barratt J, Cattran DC, Cook HT, Coppo R, Haas M, et al. Oxford classification of IgA nephropathy 2016: an update from the IgA Nephropathy Classification Working Group. Kidney Int. 2017;91:1014-21.

4. Chang A, Kowalewska J, Smith KD, Nicosia RF, Alpers CE. A clinicopathologic study of thrombotic microangiopathy in the setting of IgA nephropathy. Clin Nephrol. 2006;66:397-404.

5. El Karoui K, Hill GS, Karras A, Jacquot C, Moulonguet L, Kourilsky O, et al. A clinicopathologic study of thrombotic microangiopathy in IgA nephropathy. J Am Soc Nephrol. 2012;23:137-48.

6. Sethi S, Fervenza FC. Standardized classification and reporting of glomerulonephritis. Nephrol Dial Transplant. 2018;34:193-9.

7. Maillard N, Wyatt RJ, Julian BA, et al. Current understanding of the role of complement in IgA nephropathy. J Am Soc Nephrol. 2015;26:1503-12.

8. Daha MR, van Kooten C. Role of complement in IgA nephropathy. J Nephrol. 2015;29:1-4.

9. Wyatt RJ, Julian BA, Galla JH. Properdin deficiency with IgA nephropathy. N Engl J Med. 1981;305:1097.

10. Wyatt RJ, Julian BA, Weinstein A, Rothfield NF, McLean RH. Partial $\mathrm{H}$ (beta $1 \mathrm{H}$ ) deficiency and glomerulonephritis in two families. J Clin Immunol. 1982;2:110-7.

11. Wyatt RJ, Schneider PD, Alpers CE, Hudson EC, Julian BA. C4B deficiency in two siblings with IgA nephropathy. Am J Kidney Dis. 1990;15:66-71.

12. Gharavi AG, Kiryluk K, Choi M, Li Y, Hou P, Xie J, et al. Genome-wide association study identifies susceptibility loci for IgA nephropathy. Nat Genet. 2011;43:321-7.

13. Kiryluk K, Li Y, Scolari F, Sanna-Cherchi S, Choi M, Verbitsky $\mathrm{M}$, et al. Discovery of new risk loci for IgA nephropathy implicates genes involved in immunity against intestinal pathogens. Nat Genet. 2014;46:1187-96.

14. Kiryluk K, Novak J. The genetics and immunobiology of IgA nephropathy. J Clin Invest. 2014;124:2325-32.
15. Ring T, Pedersen BB, Salkus G, Goodship TH. Use of eculizumab in crescentic IgA nephropathy: proof of principle and conundrum? Clin Kidney J. 2015;8:489-91.

16. Rosenblad T, Rebetz J, Johansson M, Bekassy Z, Sartz L, Karpman D. Eculizumab treatment for rescue of renal function in IgA nephropathy. Pediatr Nephrol. 2014;29:2225-8.

17. Herzog AL, Wanner C, Amann K, Lopau K. First treatment of relapsing rapidly progressive $\operatorname{IgA}$ nephropathy with Eculizumab after living kidney donation: a case report. Transplant Proc. 2017;49:1574-7.

18. Nakamura H, Anayama M, Makino M, Makino Y, Tamura K, Nagasawa M. Atypical hemolytic uremic syndrome associated with complement factor $\mathrm{H}$ mutation and $\operatorname{IgA}$ nephropathy: a case report successfully treated with Eculizumab. Nephron. 2018;138:324-7.

19. Espinosa M, Ortega R, Sanchez M, Segarra A, Salcedo MT, Gonzalez F, et al. Association of $\mathrm{C} 4 \mathrm{~d}$ deposition with clinical outcomes in IgA nephropathy. Clin J Am Soc Nephrol. 2014;9:897-904.

20. Chua JS, Baelde HJ, Zandbergen M, Wilhelmus S, van Es LA, de Fijter JW, et al. Complement factor C4d is a common denominator in thrombotic microangiopathy. J Am Soc Nephrol. 2015;26:2239-47.

21. Ozen S, Pistorio A, Iusan SM, Bakkaloglu A, Herlin T, Brik R, et al. EULAR/PRINTO/PRES criteria for Henoch-Schonlein purpura, childhood polyarteritis nodosa, childhood Wegener granulomatosis and childhood Takayasu arteritis: Ankara 2008. Part II: Final classification criteria. Ann Rheum Dis. 2010;69: 798-806

22. Chobanian AV, Bakris GL, Black HR, Cushman WC, Green LA, Izzo JL, Jr., et al. The Seventh Report of the Joint National Committee on Prevention, Detection, Evaluation, and Treatment of High Blood Pressure: the JNC 7 report. JAMA. 2003;289: 2560-72.

23. Falkner B, Daniels SR, Flynn JT, Gidding S, Green LA, Ingelfinger JR, et al. The fourth report on the diagnosis, evaluation, and treatment of high blood pressure in children and adolescents. Pediatrics. 2004;114:555-76.

24. Levey AS, Bosch JP, Lewis JB, Greene T, Rogers N, Roth D. A more accurate method to estimate glomerular filtration rate from serum creatinine: a new prediction equation. Modification of Diet in Renal Disease Study Group. Ann Intern Med. 1999;130: 461-70.

25. Schwartz GJ, Munoz A, Schneider MF, Mak RH, Kaskel F, Warady BA, et al. New equations to estimate GFR in children with CKD. J Am Soc Nephrol. 2009;20:629-37.

26. Haas M, Verhave JC, Liu Z-H, Alpers CE, Barratt J, Becker JU, et al. A multicenter study of the predictive value of crescents in IgA nephropathy. J Am Soc Nephrol. 2017;28:691-701.

27. Goodship THJ, Cook HT, Fakhouri F, Fervenza FC, FrémeauxBacchi V, Kavanagh D, et al. Atypical hemolytic uremic syndrome and C3 glomerulopathy: conclusions from a "Kidney Disease: Improving Global Outcomes" (KDIGO) Controversies Conference. Kidney Int. 2017;91:539-51.

28. Pencina MJ, D'Agostino RB. Overall $\mathrm{C}$ as a measure of discrimination in survival analysis: model specific population value and confidence interval estimation. Stat Med. 2004;23:2109-23.

29. Nasri H, Mortazavi M, Ghorbani A, Shahbazian H, Kheiri S, Baradaran A, et al. Oxford-MEST classification in IgA nephropathy patients: a report from Iran. J Nephropathol. 2012;1:31-42.

30. Oruc M, Durak H, Yalin SF, Seyahi N, Altiparmak MR, Trabulus S. A rare presentation of immunoglobulin A nephropathy: acute kidney injury. Nephron. 2017;137:8-14.

31. Zhang Y, Sun L, Zhou S, Xu Q, Xu Q, Liu D, et al. Intrarenal arterial lesions are associated with higher blood pressure, reduced 
renal function and poorer renal outcomes in patients with IgA nephropathy. Kidney Blood Press Res. 2018;43:639-50.

32. Sinniah R, Gan HC, Yoon KH. Primary antiphospholipid antibody syndrome and mesangial IgA glomerulonephritis. Am J Nephrol. 2001;21:134-40.

33. Silva MF, Pimentel FL, Faria MS, Carvalho-Costa AE, Nunes JP. $\operatorname{IgA}$ nephropathy and antiphospholipid syndrome. Nephron. 1999;83:95-6.

34. Sevillano AM, Cabrera J, Gutierrez E, Morales E, Merida E, Huerta A, et al. Malignant hypertension: a type of IgA nephropathy manifestation with poor prognosis. Nefrologia. 2015;35: 42-9.

35. Dvanajscak Z, Karl BE, Sanchez AP, Walavalkar V. IgAdominant glomerulopathy and thrombotic microangiopathy after chemotherapy. Kidney Int Rep. 2018;3:492-7.

36. Surmeli-Doven S, Delibas A, Gurses I, Kayacan UR, CoskunYilmaz B, Esen K, et al. Hemolytic uremic syndrome and IgA nephropathy in a child: coincidence or not? Turk $\mathrm{J}$ Pediatr. 2018;60:81-5.

37. Tomita M, Ochiai M, Shu S, Yamauchi Y, Shihara H, Ogata A, et al. A case of thrombotic microangiopathy with glomerular subendothelial $\operatorname{IgA}$ deposition due to bevacizumab. Nihon Jinzo Gakkai Shi. 2014;56:612-7.

38. Mathew RO, Nayer A, Asif A. The endothelium as the common denominator in malignant hypertension and thrombotic microangiopathy. J Am Soc Hypertens. 2016;10:352-9.

39. Timmermans S, Abdul-Hamid MA, Vanderlocht J, Damoiseaux J, Reutelingsperger $\mathrm{CP}$, van Paassen $\mathrm{P}$, et al. Patients with hypertension-associated thrombotic microangiopathy may present with complement abnormalities. Kidney Int. 2017;91:1420-5.

40. Coppo R, Peruzzi L, Loiacono E et al. Defective gene expression of the membrane complement inhibitor CD46 in patients with progressive immunoglobulin A nephropathy. Nephrol Dial Transplant. 2018. Epub ahead of print: https://doi.org/10.1093/ ndt/gfy064.

41. Schmitt R, Krmar RT, Kristoffersson A, Soderberg M, Karpman D. IgA nephropathy associated with a novel $\mathrm{N}$-terminal mutation in factor H. Eur J Pediatr. 2011;170:107-10.

42. Zhu L, Guo WY, Shi SF, Liu LJ, Lv JC, Medjeral-Thomas NR, et al. Circulating complement factor H-related protein 5 levels contribute to development and progression of $\operatorname{IgA}$ nephropathy. Kidney Int. 2018;94:150-8.

43. Matsumura D, Tanaka A, Nakamura T, Sato E, Node K. Coexistence of atypical hemolytic uremic syndrome and crescentic $\operatorname{IgA}$ nephropathy treated with eculizumab: a case report. Clin Nephrol Case Stud. 2016;4:24-8.

44. Fabiano RCG, de Almeida Araujo S, Bambirra EA, Oliveira EA, Simoes ESAC, Pinheiro SVB. Mesangial C4d deposition may predict progression of kidney disease in pediatric patients with IgA nephropathy. Pediatr Nephrol. 2017;32:1211-20.

45. Segarra A, Romero K, Agraz I, Ramos N, Madrid A, Carnicer C, et al. Mesangial C4d deposits in early IgA nephropathy. Clin J Am Soc Nephrol. 2018;13:258-64.

46. Roos A, Rastaldi MP, Calvaresi N, Oortwijn BD, Schlagwein N, van Gijlswijk-Janssen DJ, et al. Glomerular activation of the lectin pathway of complement in IgA nephropathy is associated with more severe renal disease. J Am Soc Nephrol. 2006;17:1724-34.

47. Coppo R. C4d deposits in IgA nephropathy: where does complement activation come from? Pediatr Nephrol. 2017;32: 1097-101.

48. Paunas TIF, Finne K, Leh S, Marti HP, Mollnes TE, Berven F, et al. Glomerular abundance of complement proteins characterized by proteomic analysis of laser-captured microdissected glomeruli associates with progressive disease in IgA nephropathy. Clin Proteomics. 2017;14:30-41.

49. Yin W, Ghebrehiwet B, Weksler B, Peerschke EI. Classical pathway complement activation on human endothelial cells. Mol Immunol. 2007;44:2228-34.

50. Oikonomopoulou K, Ricklin D, Ward PA, Lambris JD. Interactions between coagulation and complement-their role in inflammation. Semin Immunopathol. 2012;34:151-65.

51. Brocklebank V, Kavanagh D. Complement C5-inhibiting therapy for the thrombotic microangiopathies: accumulating evidence, but not a panacea. Clin Kidney J. 2017;10:600-24.

52. Mengel M, Chan S, Climenhaga J, Kushner YB, Regele H, Colvin $\mathrm{RB}$ et al. Banff initiative for quality assurance in transplantation (BIFQUIT): reproducibility of $\mathrm{C} 4 \mathrm{~d}$ immunohistochemistry in kidney allografts. Am J Transplant. 2013;13:1235-45.

53. Coppo R. Biomarkers and targeted new therapies for IgA nephropathy. Pediatr Nephrol. 2017;32:725-31. 